\title{
Meninjau Faktor Keberhasilan Implementasi Enterprise Resource Planning: Perspektif Organisasi
}

\author{
Nadra Ali Akbar ${ }^{1}$ \\ Fakultas Ekonomi dan Bisnis \\ Universitas Airlangga, Indonesia. \\ Email: Nadraaliakbar@gmail.com
}

\begin{abstract}
ABSTRAK
Beberapa penelitan sebelumnya menilai kunci keberhasilan implementasi ERP merupakan keberhasilan dari organisasi tersebut. Tujuan dari penelitian ini adalah untuk menganalisis dan mengevaluasi kembali faktor-faktor yang mempengaruhi keberhasilan implementasi ERP dalam prespektif organisasi. Desain penelitian ini menggunakan metode kuantitatif deskriptif. Data yang digunakan adalah data primer dengan kuesioner sebagai pengumpulan data. Teknis analisis data menggunakan regresi linier berganda. Sejumlah 60 responden yang berhasil didapatkan berasal dari perusahaan jasa, manufaktur dan perbankan di kota Surabaya. Bedasarkan hasil analisis regresi budaya organisasi dan kepemimpinan organisasi memiliki hubungan positf dan signifikan terhadap keberhasilan implementasi ERP. Sedangkan dukungan manajemen puncak dan lingkungan organisasi tidak memiliki hubungan secara signifikan terhadap keberhasilan implementasi ERP.
\end{abstract}

Kata Kunci : $\quad$ Implementasi ERP; Organization; Leadership.

\section{Reviewing the Success Factors Implementing Enterprise Resource Planning: Organizational Perspectives}

\section{ABSTRACT}

Some previous studies assess the key to successful ERP implementation is the success of the organization. The purpose of this study is to analyze and re-evaluate the factors that influence the success of ERP implementation in an organizational perspective. The design of this study used descriptive quantitative methods. The data used are primary data with questionnaires as data collection. Technical analysis of data using multiple linear regression. A total of 60 respondents were obtained from service, manufacturing and banking companies in the city of Surabaya. Based on the results of the regression analysis of organizational culture and organizational leadership has a positive and significant relationship to the success of ERP implementation. While the support of top management and organizational environment does not have a significant relationship to the success of ERP implementation.

Keywords :

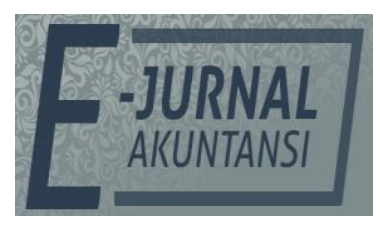

E-JA

e-Jurnal Akuntansi e-ISSN 2302-8556

Vol. 29 No. 2

Denpasar, November

2019

Hal. 535-546

Artikel masuk:

5 September 2019

Tanggal diterima:

21 Oktober 2019 


\section{PENDAHULUAN}

Enterprise resource planning (ERP) adalah perangkat lunak yang dapat menghubungkan dan menyelaraskan informasi antara berbagai divisi dalam suatu perusahaan lebih lanjut lagi menurut Yang dan Su (2009) enterprise resource planning $(E R P)$ adalah serangkaian modul aplikasi yang dapat menghubungkan operasi back-office dan operasi front-office, serta rantai pasokan internal dan eksternal. Sistem ERP terdiri dari beberapa modul, seperti sumber daya manusia, penjualan, keuangan, dan produksi, yang dapat dikustomisasi hingga batas tertentu untuk kebutuhan spesifik organisasi (Bintoro dkk., 2015). Keberadaan sistem ERP dari berbagai divisi dapat menggunakan informasi yang terintegrasi dengan baik dan dapat digunakan untuk pengambilan keputusan dalam perusahaan secara tepat waktu, konsisten, dan andal untuk berbagai divisi perusahaan. Penerapan sistem ERP sangat berguna sekali bagi setiap divisi dalam perusahaan. Brazel \& Dang (2008) mengatakan bahwa dengan mengadopsi sistem ERP, sebuah perusahaan maupun organisasi dapat menciptakan respon pasar yang positif serta dapat meningkatkan kinerja operasional. Kontribusi yang paling penting dari sistem ERP menunjukkan bahwa sistem ERP secara signifikan dalam mengurangi waktu untuk menyelesaikan segala proses bisnis serta membantu sebuah perusahaan maupun organisasi untuk mendapatkan berbagai informasi perusahaan (Hunton et al., 2003).

Dalam mengimplementasikan sistem ERP ditemukan berbagai macam kegagalan. Banyak kegagalan bahkan di dalam sebuah perusahaan besar yang memiliki sumberdaya yang dibutuhkan untuk melakukan implementasi sistem ERP yang baik (Bingi et al., 1999). Kegagalan dalam sistem ERP disebabkan karena pelatihan dalam pengguna masih kurang memadai, kurangnya komitmen user, tidak adanya perubahan dalam kegiatan manajemen (Kemp \& Low, 2008). Hal ini juga didukung oleh penelitian yang dilakukan oleh Bhatti (2005) yang mengatakan bahwa kegagalan dalam mengimplementasikan sistem Enterprise resource planning (ERP) adalah kurangnya dukungan manajemen puncak, resistensi dari karyawan, pemilihan sistem ERP dan vendor yang buruk, serta hasil akhir yang buruk.Dilihat dari tingkat kegagalan dalam mengimplementasikan sistem ERP sangat tinggi dan dapat merusak proses dari bisnis perusahaan, ada alasan kuat untuk menyelidiki faktor-faktor yang dapat mempengaruhi keberhasilan implementasi (ERP) dalam perusahaan maupun organisasi (Singh \& Wesson, 2009) (Somers \& Nelson, 2004).

Beberapa literatur terdahulu yang membahas mengenai dampak organisasiterhadap keberhasilan implementasi seperti (Romm, Pliskin et al., 1991), (Ke \& Wei, 2008), (Upadhyay et al., 2011), (Schniederjans \& Yadav, 2013) dan juga implementasi ERP yang dikaitkan pada kinerja perusahaan (Yang \& $\mathrm{Su}, 2009$ ). Tujuan utama dari penelitian ini adalah untuk mengeksplorasi lebih lanjut hubungan antara keberhasilan implementasi ERP dalam perspektif organisasi dan kepemimpinan. Pada penelitian ini akan berfokus pada organisasi dan kepemimpinan yang ada dan membagi menjadi dua bagian. Organisasi yang akan dibahas mengenai budaya dan lingkungan organisasi sedangkan kepemimpinan akan membahas tentang dukungan manajemen puncak dan kepemimpinan organisasinya. 
Teori kontingensi berpendapat bahwa tidak ada satu pun cara terbaik untuk menyusun dan mengelola organisasi. Sebaliknya, struktur dan manajemen bergantung pada sifat lingkungan di mana organisasi berada, dimana karakteristik lingkungan mempengaruhi kemampuan organisasi untuk memperoleh sumber daya dan untuk memaksimalkan kemungkinan mendapatkan akses ke sumber daya (Chenhall, 2006). Teori ini menyarankan bahwa struktur organisasi yang sesuai akan tergantung pada lingkungan keseluruhan dimana manajer harus mengindentifikasi faktor kontigensi yang akan mempengaruhi organsasi. Jika faktor kontingensi juga sesuai dengan lingkungan di mana sistem ERP sedang dilaksanakan, hal itu dapat meningkatkan kemungkinan bahwa manfaat eksternal dan internal akan bertambah selama dan pasca implementasi ERP (Elmeziane \& Elmeziane, 2012). Adanya perubahan dalam manajemen mengharuskan perusahaan melihat berbagai faktor yang dapat menghambat perubahan yang berhasil misalnya, dibutuhkan pendidikan dan kemampuan yang cukup memadai bagi pengguna sistem ERP untuk mengimplementasikan sistem ERP dengan mudah dan budaya organisasi dalam perusahaan harus menerima semua perubahan itu sendiri. Dengan manajemen mempertimbangkan budaya organisasi dan penerimaan perubahan khusus secara keseluruhan, akan ada kemungkinan bahwa pengguna sistem ERP lebih mampu memfasilitasi implementasi ERP dengan sukses (Schniederjans \& Yadav, 2013).

Budaya organisasi berguna untuk memahami keberhasilan implementasi ERP seperti yang dinyatakan oleh penelitian (Johnson et al., 2005) (Nah et al., 2007) (Schniederjans \& Yadav, 2013) (Upadhyay et al., 2011). Budaya organisasi meliputi pengalaman kolektif, nilai-nilai, keyakinan, dan perilaku norma. Hal ini memberikan pembelajaran dan inovasi organisasi, yang akan memengaruhi keberhasilan atau kegagalan ERP (Thavapragasam, 2003). Implementasi yang efektif dari sistem ERP mengharuskan organisasi untuk benar benar mematangkan struktural, teknis, organisasi, dan budaya mereka (Pishdad \& Haider, 2013) (Schein, 2009). Dalam tahap siklus hidup proyek ERP, Budaya organisasi harus dikelola untuk penggunaan yang efektif dari penerapan sistem ERP. Budaya yang dinilai dengan nilai-nilai bersama dan tujuan bersama untuk menuju kesuksesan di dalam perusahaan (Robey et al., 2002). Pemikiran yang terbuka untuk berubah dan komitmen yang kuat untuk menggunakan sistem guna mencapai tujuan bisnis akan membantu dalam upaya implementasi keberhasilan ERP (McCredie \& Updegrove, 1999). Thavapragasam (2003) membahas mengenai gagasan pengaruh budaya pada kepuasan pengguna dengan ERP. Dia berpendapat bahwa bagaimana dimensi budaya yang dikembangkan oleh Hofstede (1984) dapat digunakan untuk memahami penerapan budaya organisasi yang berbeda yang mungkin ada di antara para pengguna sistem ERP. Dimana budaya organisasi yang diterapkan diberbagai perusahaan akan mempengaruhi keberhasilan implementasi ERP.

$\mathrm{H}_{1}$ : Budaya organisasi berpengaruh signifikan terhadap keberhasilan Implementasi ERP.

Dukungan manajemen puncak telah ditekankan menjadi faktor penting keberhasilan implementasi ERP oleh banyak literatur sebelumnya (Al-Mashari \& Al-Mudimigh, 2003) (Zhang et al., 2005). Ngai et al., (2008) mengklaim organisasi 
atau perusahaan yang berskala besar dan membutuhkan sumber daya yang luas memerlukan dukungan manajemen puncak untuk implementasi ERP. AlMashari \& Al-Mudimigh (2003) menyarankan bahwa dukungan manajemen puncak harus pada seluruh proses implementasi ERP tidak ghanya pada tahap memfasilitasi dan menginisiai saja. Tugas manajemen puncak tidak hanya untuk memantau kemajuan implementasi dan memberikan arah proyek yang jelas, namun juga harus bersedia untuk memungkinkan perubahan pola pikir dengan menerima bahwa banyak pembelajaran harus dilakukan di semua tingkatan (Annamalai \& Ramayah, 2013). Menurut Zhang et al., (2005) dalam proyek implementasi ERP dukungan manajemen puncak memilikidua tugas utama yakni menyediakan sumber daya yang dibutuhkan dan menyediakan kepemimpinan untuk menunjang keberhasilan implementasi. Tanggung jawab manajemen puncak dalam implementasi ERP termasuk mengkomunikasikan strategi perusahaan untuk semua anggota organisasi, mengembangkan pemahaman tentang pembatasan dan kemampuan, menunjukkan komitmen, dan menetapkan tujuan rasional untuk keberhasilan implementasi ERP (Umble et al., 2003).

$\mathrm{H}_{2}$ : Dukungan manajemen puncak berhubungan signifikan terhadap keberhasilan Implementasi ERP.

Berbagai studi literatur sebelumnya telah menunjukkan bahwa kepemimpinan organisasi merupakan faktor penting untuk efektivitas adopsi ERP dan perubahan budaya organisasi (Al-Mashari \& Al-Mudimigh, 2003) (Vera \& Crossan, 2004) (Schniederjans \& Yadav, 2013). Pada hakikatnya pemimpin merupakan seseorang yang memiliki kapasitas untuk mempengaruhi perilaku orang lain pada kineranya dengan menggunakan kekuasaan (Oetama, 2016). Kepemimpinan organisasi memiliki peran yang penting dimana seorang pemimpin dengan gaya kepemimpinan yang tepat akan dapat membantu keberhasilan implementasi sistem ERP (Wijayanto, 2013). Selain itu, seorang pemimpin harus memiliki pengetahuan yang cukup tentang kebutuhan pengguna ERP ketika datang untuk menerapkan sistem ERP. Jika manajemen memperhitungkan kebutuhan pengguna dan membuat keputusan strategis yang memadai, kemungkinan implementasi ERP akan berhasil.

$\mathrm{H}_{3}$ : Kepemimpinan organisasi berhubungan signifikan terhadap keberhasilan Implementasi ERP.

Menurut Ives et al., (1980) lingkungan organisasi ditunjukan dengan tujuan organisasi, tugas, struktur dan gaya manajemen yang dapat mempengaruhi sebagian atau keseluruhan suatu kelompok dalam konteks ini adalah implementasi ERP dimana tingkat sentralisasi atau desentralisasi organisasi dapat tercermin dalam kontrol pengembangan sistem informasi yang diterapkan. Dalam model Ives et al., (1980) terdapat 3 dampak eksternal lingkungan organisasi yang mempengaruhi penerapan sistem informasi yaitu lingkungan pengguna, Lingkungan pengembangan sistem informasi dan lingkungan operasi system informasi. Hasil dari model tersebut menytakan bahwa karakteristik lingkungan menentukan sumber daya dan kendala, yang menentukan ruang lingkup dan bentuk setiap subsistem informasi (Ives et al., 1980). Dezdar \& Ainin (2011) juga menggunakan lingkungan organisasi dalam menganalisis faktor keberhasilan adopsi ERP dengn mengintergrasikan model termasuk lingkungan 
proyek ERP, lingkungan organisasi dan lingkungan sistem ERP. Menurutnya bahwa lingkungan proyek ERP adalah salah satu faktor utama untuk memastikan keberhasilan implementasi ERP di Iran.

$\mathrm{H}_{4}$ : Lingkungan organisasi secara signifikan terkait dengan Implementasi ERP.

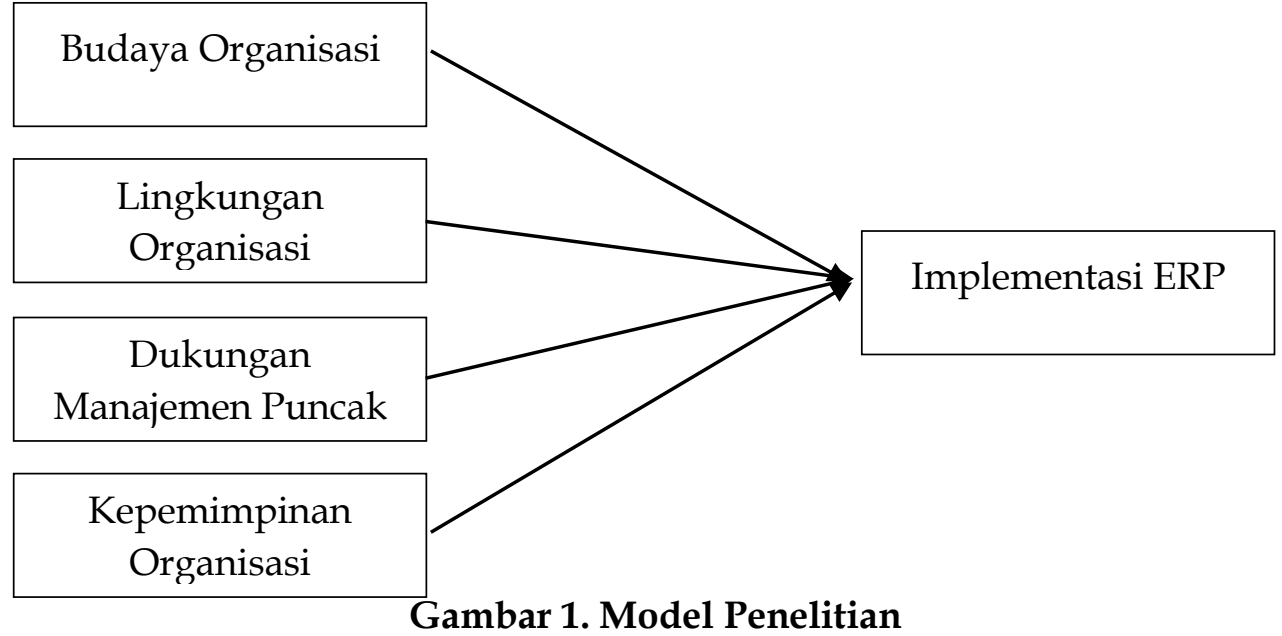

Sumber: Data Penelitian, 2019

\section{METODE PENELITIAN}

Penelitian ini merupakan penelitian ekspalantori dimana merupakan penelitian yang mencari pengaruh variabel-variabel tertentu terhadap variabel lain dalam kondisi yang dikontrol ketat yang memiliki hubungan kausal (Sugiyono, 2014). Jenis data yang digunakan adalah data kuantitatif, sedangkan data dikumpulkan dengan menggunakan penyebaran kuesioner. Kuesioner digunakan untuk mengumpulkan data empiris untuk penelitian ini. Item yang digunakan dalam operasi konstruksi diadaptasi dari studi sebelumnya yang relevan (Muscatello \& Chen, 2008) (Zhang et al., 2005).

Populasi dari penelitian ini adalah perusahaan jasa, manufaktur dan perbankan yang berlokasi di kota surabaya dengan sampel karyawan yang menggunakan ERP dalam menunjang dalam aktivitas kerja. Sampel data terkumpul sebesar 60 responden. Metode analisis data yang digunakan menggunakan uji analisis regresi berganda menggunakan perangkat lunak SPSS 25. Variabel dependen penelitian ini Implementasi ERP. Sedangkan variabel independenya diantaranya budaya organisasi, lingkungan organisasi, dukungan manajemen puncak, kepemimpinan organisasi.

\section{HASIL DAN PEMBAHASAN}

Tabel 1. menggambarkan profil demografi responden. Dapat dilihat bahwa ada lebih banyak pria daripada wanita yaitu sebesar 58,3\%. Persentase tertinggi untuk pendidikan adalah memiliki tingkat kelulusan 73,3\%. Dalam hal pengalaman kerja, ditemukan bahwa 73,3\% telah bekerja selama lebih dari 1 tahun di perusahaan mereka. Untuk bidang pekerjaan, $66,7 \%$ responden bekerja di bidang jasa. Statistik ini menyiratkan bahwa responden sangat berpengalaman dan banyak akal dengan ERP organisasi mereka, oleh karena itu, mereka adalah informan terbaik untuk berpartisipasi dalam survei. 
Tabel 1. Profil Demografi Responden

\begin{tabular}{|c|c|c|c|}
\hline Kategori & Frekuensi & $\%$ & Kumulatif \\
\hline \multicolumn{4}{|l|}{ Jenis Kelamin } \\
\hline Pria & 35 & 58,3 & 58,3 \\
\hline Wanita & 25 & 41,7 & 100 \\
\hline \multicolumn{4}{|l|}{ Pendidikan } \\
\hline SMA & 2 & 3,3 & 100 \\
\hline D3 & 8 & 13,3 & 13,3 \\
\hline S1 & 44 & 73,3 & 96,7 \\
\hline S2 & 6 & 10 & 23,3 \\
\hline \multicolumn{4}{|l|}{ Lama Bekerja } \\
\hline Kurang dari 1 tahun & 16 & 26,7 & 26,7 \\
\hline Lebih dari 1 tahun & 44 & 73,3 & 100 \\
\hline \multicolumn{4}{|l|}{ Bidang Kerja } \\
\hline Jasa & 40 & 66,7 & 66,7 \\
\hline Lainya & 9 & 15 & 81,7 \\
\hline Perbankan & 4 & 6,7 & 88,3 \\
\hline Manufaktur & 7 & 11,7 & 100 \\
\hline
\end{tabular}

Sumber: Data Penelitian, 2019

Tahap pertama yang dilakukan adalah uji reliabilitas untuk mengukur konsistensi alat ukur dalam mengukur konsistensi responden dalam menjawab setiap item pernyataan dalam kuesioner atau instrument penelitian. Tabel 2. menunjukan hasil analisis reliabilitas untuk semua indikator variabel pengukuran yang ditunjukkan dari nilai Cronbach's Alpha Budaya Organisasi 0,808, Dukungan Manajemen Puncak 0,812, Kepemimpinan Organisasi 0,741, Lingkungan Organisasi 0,662 dan Implementasi ERP 0,852. Dapat dikatakan bahwa semua indikator pengukuran variabel telah lulus uji reliabilitas karena nilai alpha cronbach lebih dari 0,6. Jadi, dapat disimpulkan bahwa konstruk pada setiap variabel indikator dapat dikatakan valid dan reliabel.

Tabel 2. Hasil Pengujian Reliabilitas

\begin{tabular}{lccl}
\hline \multicolumn{1}{c}{ Konstruk Variabel } & $\begin{array}{c}\text { N of } \\
\text { item }\end{array}$ & $\begin{array}{c}\text { Cronbach's } \\
\text { Alpha }\end{array}$ & Keterangan \\
\hline Budaya Organisasi & 2 & .808 & Reliabel \\
Dukungan manajemen puncak & 2 & .812 & Reliabel \\
Kepemimpinan Organisasi & 3 & .741 & Reliabel \\
Lingkungan Organisasi & 3 & .904 & Reliabel \\
Implementasi ERP & 5 & .852 & Reliabel \\
\hline
\end{tabular}

Sumber: Data Penelitian, 2019

Tahap kedua adalah pengujian multikolinearitas. Uji ini ditujukan untuk mengidentifikasi adanya permasalahan multikolineratitas antar variabel yang akan diuji. Dasar pengambilan keputusan dalam uji multikolineritas dapat dilakukan dengan cara melihat nilai tolerance dan VIF. Nilai hasil pengujian multikolinearitas menunjukan bahwa semua nilai tolerance untuk semua variabel lebih besar dari 0,1. Sementara nilai VIF untuk semua variabel kurang 
dari 10. Maka dapat disimpulkan bahwa data yang digunakan tidak terjadi gejela multikolineritas.

Tabel 3. Hasil pengujian Multikolineritas

\begin{tabular}{|c|c|c|c|c|c|c|c|}
\hline \multirow[t]{2}{*}{ Model } & \multicolumn{2}{|c|}{$\begin{array}{l}\text { Unstandardized } \\
\text { Coefficients }\end{array}$} & \multirow{2}{*}{$\frac{\begin{array}{c}\text { Standardized } \\
\text { Coefficients }\end{array}}{\text { Beta }}$} & \multirow[t]{2}{*}{$\mathrm{t}$} & \multirow[t]{2}{*}{ Sig. } & \multicolumn{2}{|c|}{$\begin{array}{l}\text { Collinearity } \\
\text { Statistics }\end{array}$} \\
\hline & B & $\begin{array}{l}\text { Std. } \\
\text { Error }\end{array}$ & & & & Tolerance & VIF \\
\hline (Constant) & 0,926 & 0,379 & & 2,442 & 0,018 & & \\
\hline $\begin{array}{l}\text { Budaya } \\
\text { Organisasi }\end{array}$ & 0,351 & 0,12 & 0,383 & 2,927 & 0,005 & 0,41 & 2,438 \\
\hline $\begin{array}{l}\text { Dukungan } \\
\text { Manajemen } \\
\text { Puncak }\end{array}$ & 0,044 & 0,112 & 0,05 & 0,395 & 0,694 & 0,439 & 2,279 \\
\hline $\begin{array}{l}\text { Kepemimpinan } \\
\text { Organisasi }\end{array}$ & 0,558 & 0,138 & 0,554 & 4,037 & 0 & 0,373 & 2,684 \\
\hline $\begin{array}{l}\text { Lingkungan } \\
\text { Organisasi }\end{array}$ & $-0,189$ & 0,135 & $-0,177$ & $-1,394$ & 0,169 & 0,434 & 2,303 \\
\hline
\end{tabular}

a. Dependent Variable: IMPLEMENTASI ERP

Sumber: Data penelitian, 2019

Tahapan yang dilakukan selanjutnya adalah melakukan uji regresi berganda untuk menguji pengaruh variabel independen terhadap variabel dependennya (implementasi ERP). Pengujian ANOVA untuk menentukan apakah model penelitian yang digunakan layak uji atau tidak. Bedasarkanhasil uji ANOVA menunjukkan bahwa model yang digunakan layak untuk diuji dapat dilihat dari tingkat signifikansi 0.000 pada taraf signifikan a $5 \%$.

Koefisien determinasi $\left(\mathrm{R}^{2}\right)$ yang menunjukkan semua kemampuan variabel bebas secara bersama-sama dalam menjelaskan varian dari perubahan variabel terikat. Berdasarkan hasil estimasi model regresi, diperoleh $\mathrm{R}^{2}$ sebesar 0.586 (58 $\%$ ). Hasil estimasi tersebut menujukkan bahwa variasi dalam variabel dependen keberhasilan implementasi ERP dapat dijelaskan sebesar $58,6 \%$ oleh variasi dalam variabel independen yaitu budaya organisasi, dukungan manajemen puncak, kepemimpinan organisasi, lingkungan organisasi dan sisanya sebesar $41,4 \%$ dijelaskan oleh variabel lain di luar model.

Tabel 4. Hasil Regresi Berganda

\begin{tabular}{|c|c|c|c|c|c|}
\hline \multirow[t]{2}{*}{ Model } & \multicolumn{2}{|c|}{$\begin{array}{l}\text { Unstandardized } \\
\text { Coefficients }\end{array}$} & \multirow{2}{*}{$\begin{array}{c}\begin{array}{c}\text { Standardized } \\
\text { Coefficients }\end{array} \\
\text { Beta }\end{array}$} & \multirow[b]{2}{*}{$\mathrm{t}$} & \multirow[b]{2}{*}{ Sig. } \\
\hline & $\mathrm{B}$ & Std. Error & & & \\
\hline$\overline{\text { (Constant) }}$ & 0,926 & 0,379 & & 2,442 & 0,018 \\
\hline Budaya organisasi & 0,351 & 0,120 & 0,383 & 2,927 & 0,005 \\
\hline Dukungan manajemen puncak & 0,044 & 0,112 & 0,050 & 0,395 & 0,694 \\
\hline Kepemimpinan organisasi & 0,558 & 0,138 & 0,554 & 4,037 & 0,000 \\
\hline Lingkungan organisasi & $-0,189$ & 0,135 & $-0,177$ & $-1,394$ & 0,169 \\
\hline Adjusted R Square & 0,586 & & & & \\
\hline $\mathrm{F}$ & 21.871 & & & & \\
\hline Sig. & $.000^{\mathrm{b}}$ & & & & \\
\hline
\end{tabular}

a. Dependent Variable: IMPLEMENTASI ERP

Sumber: Data Penelitian, 2019 
Berdasarkan hasil data pemrosesan dalam penelitian ini, linear berganda persamaan regresi adalah sebagai berikut.

$$
\mathrm{Y}=0,926+0,176 \mathrm{X} 1+0,044 \mathrm{X} 2+0,558 \mathrm{X} 3-0.63
$$

Bedasarkan hasil pengujian hipotesis menunjukkan bahwa nilai signifikansi sebesar 0,005 sedangkan nilai koefisien sebesar 0,176. Dari hasil ini dapat disimpulkan bahwa hipotesis 1 diterima, dimana budaya organisasi berpengaruh positif signifikan terhadap keberhasilan implemetasi ERP. Hal ini menunjukan bahwa keberhasilan implementasi ERP dapat dicapai apabila perusahaan menerapkan budaya organisasi yang baik. Budaya yang dinilai dengan nilai dan tujuan bersamauntuk menuju kesuksesan di dalam perusahaan dan juga pemikiran yang terbuka untuk berubahserta komitmen yang kuat untuk menggunakan sistem untuk mencapai tujuan bisnis akan membantu dalam upaya implementasi keberhasilan ERP (Robey et al., 2002). Hasil ini sejalan dan mendukung penelitian sebelumnya yang telah dilakukan (Ke \& Wei, 2008) yang berpendapat bahwa keberhasilan implementasi ERP berhubungan positif dengan budaya organisasi di sepanjang dimensi pembelajaran danpengembangan, pengambilan keputusan partisipatif, pembagian kekuasaan, dukungan dan kolaborasi, serta toleransi terhadap risiko dan konflik. Selain itu Annamalai \& Ramayah, (2013) menyatakan bahwa budaya organisasi memiliki dampakyang signifikan dalam penerapan sistem ERP di India. Berdasarkan pengamatan empiris, adanya pembentukan budaya organisasi dalam perusahaan melalui nilai-nilai dan keyakinan operasionalnya memberikan pengaruh besar pada bagaimana karyawan dapat memahami perubahan yang ada. Dengan adanya kolaborasi, konsensus, dan kerja sama menunjukanbahwa orang-orang siap untuk berubah,hal ini merupakan suatuhal yang dibutuhkanuntuk mencapai keberhasilan penerapan budaya yang berorientasi pada keberhasilan implementasi ERP Dezdar \& Ainin, (2012).

Bedasarkan hasil pengujian hipotesis menunjukkan bahwa nilai signifikansi sebesar 0,694 sedangkan nilai koefisien sebesar 0,44. Dari hasil ini dapat disimpulkan bahwa hipotesis 2 tidak diterima, dimana dukungan manaemen puncak tidak berpengaruh terhadap keberhasilan implementasi ERP. Hasil ini menunjukan dukungan manajamen puncak dalam implementasi ERP dianggap kurang maksimal dalam keberhasilan implentasi ERP, hal ini diduga karena pengguna ERP merupakan eksekutif puncak dimana dengan latar belakang ini mungkin tidak mendapati kesulitan yang berarti dalam implementasi ERP. Disisi lain hal ini dikarenakan manajemen puncak membatasi aksesibilitas data dari berbagai departemen yang menjadi faktor penghambat dalam implementasi ERP (Badewi et al., 2018).Hasil ini tidak sejalan dengan literatur sebelumnya Dezdar \& Ainin (2011). Namun sejalan dengan penelitian Bajwa et al., (1998) yang menunjukan bahwa tidak ada hubungan langsung antaradukungan manajemen puncak terhadap keberhasilan implementasi ERP. Hal ini diperkuat Ifinedo (2008) yang mengatakan bahwa manfaat keseluruhan sistem ERP akan rendah ketika dukungan manajemen puncak rendah atau bahkan tidak ada.

Bedasarkan hasil pengujian hipotesis menunjukkan bahwa nilai signifikansi sebesar 0,000 sedangkan nilai koefisien sebesar 0,558. Dari hasil ini dapat disimpulkan bahwa hipotesis 3 diterima, dimana kepemimpinan 
organisasi berpengaruh positif signifikan terhadap keberhasilan implementasi ERP.Hasil ini sesuai dengan penelitian yang telah dilakukan (Ketchen Jr \& Hult, 2007) (Zhang et al., 2005) bahwa kepemimpinan organisasi menjadi salah satu kunci keberhasilan implementasi ERP. Dari hasil pengamatan menunjukan bahwa divisi yang memiiki kepemimpinan organisasi yang baik akan lebih cepat untuk penerapan ERP. Dalam implementasi ERP mengharuskan adanya perubahan kebiasaan para pengguna dari sistem manual menjadi terintegrasi, sehingga akan terjadi banyak penolakan dalam penerapanya. Maka dari itu, aspek kepimpinan sangat diperlukan dalam organisasi untuk keberhasilan implementasi ERP.

Bedasarkan hasil pengujian pada penelitian ini menunjukkan bahwa nilai signifikansi sebesar 0,169 dan nilai koefisien sebesar -0,63. Dari hasil ini dapat disimpulkan bahwa hipotesis 4 ditolak, dimana lingkungan organisasi tidak berpengaruh signifikan terhadap keberhasilan implementasi ERP. Hasil ini tidak sejalan dengan penenlitian Xue \& Snyder (2005) dan Zhang et al., (2005) yang menyatakan bahwa lingkungan organisasi merupakan faktor utama dalam keberhasilan implementasi ERP.Bedasarkan data empiris terdapat kemungkinan hal ini bisa terjadi pada lingkungan organisasi dalam implementasi ERP.Meskipun lingkungan organisasi cukup baik dalam mendorong karyawan untuk dapat mengimplementasikan ERP, namun apabila tidak dukungan dengan adanya pelatihan atau semacamnya menjadi tidak berguna. Maka dari itu dibutuhkan faktor lain untuk sebuah lingkungan organisasi yang baik untuk dapat mengimplementasikan ERP tersebut.

\section{SIMPULAN}

Berdasarkan pembahasan yang telah dipaparkan sebelumnya, kesimpulan yang daoat diambil dari penelitian ini adalah hanya budaya organisasi dan kepemimpinan organisasi yang berpengaruh positif dan signifikan terhadap keberhasilan implementasi ERP dengan tingkat signifikasi 5\%. Sedangkan dukungan manajemen puncak dan lingkungan organisasi tidak memiliki pengaruh signifikan terhadap keberhasilan implementasi ERP.

Perusahaan yang menerapkan ERP harus menyadari perbedaan budaya untuk melakukan pelatihan tambahan untuk mengisi kesenjangan antara tertanam dalam sistem ERP. kemungkinan implementasi ERP meningkat ketika pengguna sistem harus mau belajar bagaimana organisasi memiliki atribut budaya. Aspek kepemimpinan juga diperlukan untuk menginspirasi karyawan untuk mengubah kebiasaan dan perilaku yang sebelumnya manual menjadi terintregasi. Seorang pimpinan harus fokus pada prosedur perubahan dalam organisasi dan mengambil langkah-langkah untuk memastikan bahwa karyawan siap untuk berubah dan termotivasi untuk keberhasilan penerapan ERP.

Dalam penelitian ini terdapat berbagai keterbatasan. Diharapkan penelitian lebih lanjut dapat menambah variabel atau juga mengeksplorasi pengaruh budaya yang terjadi dalam keberhasilan implementasi ERP. karena masingmasing daerah memiliki budaya yang berbeda yang dapat menjadi peluang untuk penelitian lebih lanjut. sampel dalam penelitian ini sangat terbatas, diharapkan penelitian lebih lanjut dapat menambah untuk menjelaskan faktor keberhasilan implementasi ERP. 


\section{REFERENSI}

Al-Mashari, M., \& Al-Mudimigh, A. (2003). ERP implementation: lessons from a case study. Information Technology E People, 16(1), 21-33.

Annamalai, C., \& Ramayah, T. (2013). Does the organizational culture act as a moderator in Indian enterprise resource planning (ERP) projects? An empirical study. Journal of Manufacturing Technology Management, 24(4), 555587.

Badewi, A., Shehab, E., Zeng, J., \& Mohamad, M. (2018). ERP benefits capability framework: orchestration theory perspective. Business Process Management Journal, 24(1), 266-294.

Bajwa, D. S., Rai, A., \& Brennan, I. (1998). Key antecedents of executive information system success: a path analytic approach. Decision Support Systems, 22(1), 31-43.

Bhatti, T. R. (2005). Critical success factors for the implementation of enterprise resource planning (ERP): empirical validation. In the second international conference on innovation in information technology (Vol. 110, pp. 1-10).

Bingi, P., Sharma, M. K., \& Godla, J. K. (1999). Critical issues affecting an ERP implementation. IS Management, 16(3), 7-14.

Bintoro, B. P. K., Simatupang, T. M., Putro, U. S., \& Hermawan, P. (2015). Actors' interaction in the ERP implementation literature. Business Process Management Journal, 21(2), 222-249.

Brazel, J. F., \& Dang, L. (2008). The effect of ERP system implementations on the management of earnings and earnings release dates. Journal of Information Systems, 22(2), 1-21.

Chenhall, R. H. (2006). Theorizing contingencies in management control systems research. Handbooks of Management Accounting Research, 1, 163-205.

Dezdar, S., \& Ainin, S. (2011). The influence of organizational factors on successful ERP implementation. Management Decision, 49(6), 911-926.

Dezdar, S., \& Ainin, S. (2012). Investigating the impact of organizational culture on enterprise resource planning implementation projects. World Applied Sciences Journal, 17(9), 1125-1133.

Elmeziane, K., \& Elmeziane, M. (2012). Enterprise resources planning systems implementation success in China. Business and Management Review, 1(12), 19.

Hofstede, G. (1984). Culture's consequences: International differences in work-related values (Vol. 5). sage.

Hunton, J. E., Lippincott, B., \& Reck, J. L. (2003). Enterprise resource planning systems: comparing firm performance of adopters and nonadopters. International Journal of Accounting Information Systems, 4(3), 165-184.

Ifinedo, P. (2008). Impacts of business vision, top management support, and external expertise on ERP success. Business Process Management Journal, 14(4), 551-568.

Ives, B., Hamilton, S., \& Davis, G. B. (1980). A framework for research in computer-based management information systems. Management Science, 26(9), 910-934.

Johnson, T., Kulesa, P., Cho, Y. I., \& Shavitt, S. (2005). The relation between 
culture and response styles: Evidence from 19 countries. Journal of CrossCultural Psychology, 36(2), 264-277.

Ke, W., \& Wei, K. K. (2008). Organizational culture and leadership in ERP implementation. Decision Support Systems, 45(2), 208-218.

Kemp, M. J., \& Low, G. C. (2008). ERP innovation implementation model incorporating change management. Business Process Management Journal, 14(2), 228-242.

Ketchen Jr, D. J., \& Hult, G. T. M. (2007). Bridging organization theory and supply chain management: The case of best value supply chains. Journal of Operations Management, 25(2), 573-580.

McCredie, J., \& Updegrove, D. (1999). Enterprise System Implementations: Lessons from the Trenches. Cause/Effect, 22(4), 9-16.

Muscatello, J. R., \& Chen, I. J. (2008). Enterprise resource planning (ERP) implementations: theory and practice. International Journal of Enterprise Information Systems (IJEIS), 4(1), 63-83.

Nah, F. F.-H., Islam, Z., \& Tan, M. (2007). Empirical assessment of factors influencing success of enterprise resource planning implementations. Journal of Database Management (JDM), 18(4), 26-50.

Ngai, E. W. T., Law, C. C. H., \& Wat, F. K. T. (2008). Examining the critical success factors in the adoption of enterprise resource planning. Computers in Industry, 59(6), 548-564.

Oetama, S. (2016). Pengaruh Kepemimpinan dan Disiplin Kerja terhadap Prestasi Kerja Pegawai RSUD dr Murjani di Sampit. Jurnal Terapan Manajemen Dan Bisnis, 2(1).

Pishdad, A., \& Haider, A. (2013). ERP institutionalization: Exploring the influential factors. Journal of Enterprise Information Management, 26(6), 642660.

Robey, D., Ross, J. W., \& Boudreau, M.-C. (2002). Learning to implement enterprise systems: An exploratory study of the dialectics of change. Journal of Management Information Systems, 19(1), 17-46.

Romm, T., Pliskin, N., Weber, Y., \& Lee, A. S. (1991). Identifying organizational culture clash in MIS implementation: when is it worth the effort? Information $\mathcal{E}$ Management, 21(2), 99-109.

Schein, E. H. (2009). The corporate culture survival guide (Vol. 158). John Wiley \& Sons.

Schniederjans, D., \& Yadav, S. (2013). Successful ERP implementation: an integrative model. Business Process Management Journal, 19(2), 364-398.

Singh, A., \& Wesson, J. (2009). Evaluation criteria for assessing the usability of ERP systems. In Proceedings of the 2009 annual research conference of the South African Institute of Computer Scientists and Information Technologists (pp. 8795). ACM.

Somers, T. M., \& Nelson, K. G. (2004). A taxonomy of players and activities across the ERP project life cycle. Information $\mathcal{E}$ Management, 41(3), 257-278.

Sugiyono, P. D. (2014). Populasi dan sampel. Metode Penelitian Kuantitatif, Kualitatif Dan RED, 291, 292.

Thavapragasam, X. T. (2003). Cultural influences on ERP implementation success. In Proceedings of the first Australian undergraduate students' computing 
Conference (pp. 93-99).

Umble, E. J., Haft, R. R., \& Umble, M. M. (2003). Enterprise resource planning: Implementation procedures and critical success factors. European Journal of Operational Research, 146(2), 241-257.

Upadhyay, P., Jahanyan, S., \& Dan, P. K. (2011). Factors influencing ERP implementation in Indian manufacturing organisations: A study of micro, small and medium-scale enterprises. Journal of Enterprise Information Management, 24(2), 130-145.

Vera, D., \& Crossan, M. (2004). Strategic leadership and organizational learning. Academy of Management Review, 29(2), 222-240.

Wijayanto, H. (2013). Peran gaya kepemimpinan transformasional key user terhadap kesuksesan implementasi enterprise resource planning. Jurnal Perilaku Dan Strategi Bisnis, 1(2).

Xue, Y., Liang, H., Boulton, W. R., \& Snyder, C. A. (2005). ERP implementation failures in China: Case studies with implications for ERP vendors. International Journal of Production Economics, 97(3), 279-295.

Yang, C., \& Su, Y. (2009). The relationship between benefits of ERP systems implementation and its impacts on firm performance of SCM. Journal of Enterprise Information Management, 22(6), 722-752.

Zhang, Z., Lee, M. K. O., Huang, P., Zhang, L., \& Huang, X. (2005). A framework of ERP systems implementation success in China: An empirical study. International Journal of Production Economics, 98(1), 56-80. 